\title{
Ectosymbiosis is a critical factor in the local benthic biodiversity of the Antarctic deep sea
}

\author{
Vincent Hétérier ${ }^{1,2}$, Bruno David ${ }^{1}$, Chantal De Ridder ${ }^{2}$, Thierry Rigaud ${ }^{1, *}$ \\ ${ }^{1}$ Université de Bourgogne, Laboratoire Biogéosciences, UMR CNRS 5561, 6 bd. Gabriel, 21000 Dijon, France \\ ${ }^{2}$ Laboratoire de Biologie marine (C.P. 160/15), Université Libre de Bruxelles, 50 av. F.D. Roosevelt, 1050 Bruxelles, Belgium
}

\begin{abstract}
In deep-sea benthic environments, competition for hard substrates is a critical factor in the distribution and diversity of organisms. In this context, the occurrence of biotic substrates in addition to mineral substrates may change the characteristics of sessile fauna. We tested this hypothesis at different localities of the Weddell Sea (Antarctica) by studying the diversity of ectosymbionts living on the spines of cidaroids (echinoids). The presence of cidaroids promoted a higher total specific richness and increased sessile species abundance, but did not change the diversity. Analyses of species distribution suggested that the cidaroids are a favourable habitat for sessile organisms, compared to rocks, but are colonized by relatively specialist sessile species, leaving the unfavourable rock habitat to more generalist species. Therefore, our study highlights the role of some living organisms, such as cidaroids, as key species increasing Antarctic benthic deep-sea species richness through the niche they provide to symbiotic species.
\end{abstract}

KEY WORDS: Symbiosis · Species diversity · Species abundance · Null models · Cidaroids · Weddell Sea

Resale or republication not permitted without written consent of the publisher

\section{INTRODUCTION}

Interactions between organisms have an extensive influence on their distribution and abundance. Historically, competition, predation and ecosystem engineering were considered to be important factors controlling community structure (Jones et al. 1994, Begon et al. 1996). More recently, the importance of symbiosis, mostly the role of parasitism or mutualism, has been identified in changing other interactions (e.g. Clay \& Holah 1999, Clay 2001, Hatcher et al. 2006). However, few studies show that symbiosis can modify community structure.

Antarctic marine biodiversity is of particular interest because of the relative isolation of the Southern Ocean, its high endemism and its sensitivity to perturbations (Brey et al. 1994, Battaglia et al. 1997). Extensive investigations of Southern Ocean benthic biodiversity have taken place only within the last few decades, thanks to the ever more numerous explorations, mostly consisting of photographic surveys at all depths including the deep sea (Brey et al. 1994, Gutt \& Starmans 1998, Starmans et al. 1999, Brandt et al. 2007). The forces shaping benthic biodiversity in the Antarctic are not yet fully understood, but communities seem to be structured by bathymetry (Gutt 2000) as well as by the geography of the shelf (Clarke et al. 2007). Communities are dominated by sessile organisms, but biomass and diversity distributions are discontinuous, with patches of high abundance and diversity surrounded by quasi-deserts (Arntz et al. 1994, Gutt \& Starmans 1998, Starmans et al. 1999, Gutt 2000). The nature and accessibility of hard mineral substrates appear to be important factors affecting the distribution of benthic species (Gutt 2000). In the Southern Ocean, large areas of the deep-sea bottom are covered with poorly sorted sediments. Most of the sediments consist of mud derived from the decomposition of pelagic organisms (Tyler 1995), while hard substrates include pebbles as well as large and small rocks dropped by icebergs, the rocks having been removed from the continent by glacial erosion (Andrews et al. 
1997). Rocks are usually partly buried in the sediment, limiting the availability of these hard mineral substrates to sessile benthic organisms (Knox 1994, Tyler 1995, Andrews et al. 1997).

Biotic interspecific interactions, such as competition for access to limited substrates (Gutt 2000), have been proposed as another key factor to explain species distribution. In addition to such competition, Gutt \& Schickan (1998) suggested that epibiosis is quite common among species of the Antarctic benthos, and may govern the distribution of species richness. In case of scarcity of mineral hard substrates, biotic substrates (such as shells) can provide suitable sites for attachment and therefore new ecological niches for sessile species. Ectosymbiosis (i.e. sessile life on biotic substrate, whatever the nature of the relationship: mutualism, commensalism, or parasitism) is commonly observed in marine ecosystems (Key et al. 1996, Williams \& McDermott 2004). In the Antarctic, numerous species have been documented as epibionts or substrates, respectively (Barnes \& Clarke 1995, Gutt \& Schickan 1998); however, these studies were not able to establish the importance of ectosymbiosis in the biodiversity of sessile organisms, mainly because relative proportions of species fixed on living organisms versus those fixed on abiotic substrates were not compared at geographically restricted, homogenous sites. Therefore, it is difficult to determine if ectosymbionts are specific to their living substrate or if they are opportunistic sessile organisms, selecting other organisms as substrate because of the rarity of mineral substrates.

Among biotic substrates available in the Antarctic, a clade of echinoids (sea urchins), the Cidaroida, appears to be useful in addressing questions concerning ectosymbiosis. Echinoderms represent 55\% of the benthic biomass in the Antarctic, but the cidaroids are rare and have a patchy distribution. They can be locally abundant, however, reflecting the general pattern of benthic species distribution (Jacob et al. 2003). The shaft of their spines is not covered by an epithelium and lacks an anti-fouling mechanism (Märkel \& Röser 1983), a characteristic that allows colonization by a large number of epibionts. While several studies have described epibiosis on cidaroids, recent (e.g. Brey et al. 1993, Gutt \& Schickan 1998, Massin \& Hétérier 2004, David et al. 2005a) and fossil (Schneider 2003) analyses of epibiont diversity and specificity remain rare (Hétérier et al. 2004, Hopkins et al. 2004). Cidaroids have rarely been taken into account in exploration of epibenthic biodiversity (Ragua-Gil et al. 2004). Hétérier et al. (2004) have shown that 2 species of Antarctic cidaroids, Ctenocidaris spinosa and Rhynchocidaris triplopora, are colonized by 60 and 30 morphological types of ectosymbionts, respectively, suggesting that the presence/absence of cidaroids on the sea floor might significantly affect local biodiversity, by providing new substrates for sessile organisms. However, epibiotic assemblages on cidaroids have not been compared with assemblages living on mineral substrates.

Here, we test the role ectosymbiosis involving cidaroids plays in establishing local biodiversity of the sessile fauna in the Weddell Sea. The present study aims to answer 2 main questions: (1) What is the role played by ectosymbiosis in abundance and diversity of sessile organisms at a local scale? (2) Are organisms involved in epibiosis found only on cidaroids, or are they generalists also found on non-living substrates? To answer these questions, samples were collected, using an identical sampling procedure, at different sites of the deep Weddell Sea, and the faunas were compared according to their sites of attachment: rocks or cidaroids.

\section{MATERIALS AND METHODS}

Samples were taken between 26 January and 30 March 2005 during the expedition ANDEEP III of the RV 'Polarstern' (ANT XXII/3) in the Southern Ocean (Linse et al. 2007). Of the 15 deep-sea benthic stations sampled in the Weddell Sea area, 10 were selected for analysis in the present study. From each of these 10 stations, samples were taken using an Agassiz trawl (opening $5 \mathrm{~m}$ ). The location and depth of the stations, as well as the area and substrate sampled are given in Fig. 1 and Table 1, respectively. The stations

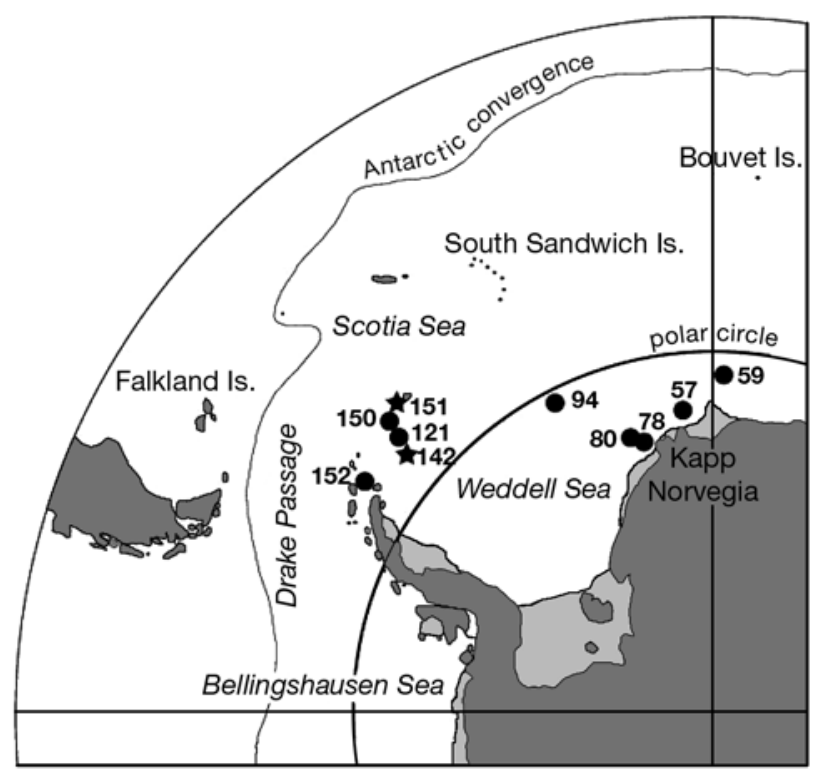

Fig. 1. Sampling stations in the Weddell Sea (stars indicate the 2 stations with cidaroids from the western group) 
Table 1. Depth, surface sampled and nature of sediments at the 10 stations sampled during ANDEEP III. Cat: categories of station location (E: eastern, W: western part of the Weddell Sea without cidaroids; $W^{*}$ : station located in the western part of the Weddell Sea with cidaroids); nr: number of rocks analyzed; nc: number of cidaroids collected; $\mathrm{Cr}$ and $\mathrm{Cc}$ : rates of colonization by sessile organisms on rocks and cidaroids, respectively; Dr: approximation of mean diameter of rocks [(length + width) / 2]; Hr: mean height of rocks; Hc: mean height of cidaroid tests with spines. Dr, Hr and Hc values are means \pm SD. Dr and Hr: calculations performed only on colonized rocks

\begin{tabular}{|c|c|c|c|c|c|c|c|c|c|c|c|c|c|}
\hline $\begin{array}{l}\text { Station } \\
\text { no. }\end{array}$ & Cat & Latitude & Longitude & $\begin{array}{c}\text { Depth } \\
\text { (m) }\end{array}$ & $\begin{array}{c}\text { Surface } \\
\text { sampled }\left(\mathrm{m}^{2}\right)\end{array}$ & $\begin{array}{c}\text { Main } \\
\text { sediments }\end{array}$ & $\mathrm{nr}$ & $\begin{array}{l}\mathrm{Cr} \\
(\%)\end{array}$ & $\begin{array}{c}\mathrm{Dr} \\
(\mathrm{mm})\end{array}$ & $\begin{array}{c}\mathrm{Hr} \\
(\mathrm{mm})\end{array}$ & $\mathrm{nc}$ & $\begin{array}{l}\mathrm{Cc} \\
(\%)\end{array}$ & $\begin{array}{l}\mathrm{Hc} \\
(\mathrm{mm})\end{array}$ \\
\hline 57 & E & $69^{\circ} 24.62^{\prime} \mathrm{S}$ & $5^{\circ} 19.68^{\prime} \mathrm{W}$ & 1822 & 1515 & Mud & 100 & 7.0 & $51.8 \pm 10.4$ & $44.1 \pm 10.4$ & 0 & - & - \\
\hline 78 & E & $71^{\circ} 9.60^{\prime} \mathrm{S}$ & $14^{\circ} 2.47^{\prime} \mathrm{W}$ & 2191 & 1610 & Mud-Rocks & 200 & 5.5 & $75.2 \pm 9.2$ & $41.4 \pm 7.7$ & 0 & - & - \\
\hline 80 & $\mathrm{E}$ & $70^{\circ} 40.42^{\prime} \mathrm{S}$ & $14^{\circ} 43.83^{\prime} \mathrm{W}$ & 2978 & 1765 & Mud-Rocks & 250 & 4.0 & $67.2 \pm 10.4$ & $35.7 \pm 6.4$ & 0 & - & - \\
\hline 94 & $\mathrm{E}$ & $66^{\circ} 38.10^{\prime} \mathrm{S}$ & $27^{\circ} 5.46^{\prime} \mathrm{W}$ & 4894 & 1720 & Mud & 100 & 7.0 & $72.9 \pm 11.4$ & $30.7 \pm 5.9$ & 0 & - & - \\
\hline 150 & $\mathrm{~W}$ & $61^{\circ} 48.20^{\prime} \mathrm{S}$ & $47^{\circ} 28.64^{\prime} \mathrm{W}$ & 1954 & 1400 & Rocks & 100 & 14.0 & $86.1 \pm 11.6$ & $48.1 \pm 8.6$ & 0 & - & - \\
\hline 151 & $\mathrm{~W}^{*}$ & $61^{\circ} 45.34^{\prime} \mathrm{S}$ & $47^{\circ} 7.78^{\prime} \mathrm{W}$ & 1188 & 1455 & Mud & 250 & 10.8 & $70.5 \pm 5.5$ & $35.5 \pm 3.1$ & $23^{b}$ & 100 & $42.4 \pm 2$. \\
\hline 152 & $\mathrm{~W}$ & $62^{\circ} 19.87^{\prime} \mathrm{S}$ & $57^{\circ} 54.09^{\prime} \mathrm{W}$ & 1998 & 1730 & Mud & 150 & 11.3 & $55.4 \pm 10.7$ & $28.5 \pm 5.8$ & 0 & - & - \\
\hline
\end{tabular}

are all below the continental shelf $(>1000 \mathrm{~m}$, Clarke \& Johnson 2003), deeper than the $1000 \mathrm{~m}$ limit below which a depth gradient vanishes in different taxonomic groups (e.g. Allcock et al. 2001, Hilbig 2001, Linse et al. 2006). The sampled stations were combined into an eastern group ('E') and a western group ('W'). Cidaroid echinoids were only found at 2 stations of the western group (subset $\mathrm{W}^{*}$ ). Cidaroids and rocks, the only available abiotic hard substrates suitable for sessile organisms, were specifically sorted, measured and counted. The area of the rocks that was originally buried versus the area that was exposed (i.e. available for settling by invertebrates) could not be easily determined after the rocks were brought up to the surface, so their total height was measured. As the number of rocks always surpassed 500 in each sample, sub-samples ranging from 100 to 250 (proportional to a rough estimate of the total number) were taken for analysis. Two species of cidaroids were found in our samples: Ctenocidaris speciosa Mortensen 1910 and Aporocidaris milleri Agassiz 1898, and they occurred only at 2 stations (Table 1). Specimens with $>5 \%$ broken spines were removed from the analyses to ensure reliability of epibiosis estimates. Cidaroids and rocks carrying at least 1 sessile organism were fixed in $70 \%$ ethanol for further analysis, and were considered as 'colonized'. The prevalence of sessile organisms was calculated as the ratio of colonized individuals to total individuals. Identification and counting of sessile species was done in the laboratory under a stereo microscope. Abundance data were obtained for each colonized individual (cidaroid or rock). For abundance data of colonial species (e.g. sponges, bryozoans, hydrozoans), for which the notion of 'individual' is ambi- guous, it is conservative to consider that a single colony was founded by 1 propagule only. Therefore, 2 colonies were considered as 2 'individuals' when they were spatially discrete (e.g. attached to different spines of a given echinoid, or attached at several separated points of a given spine or rock). Attached organisms were identified at least to the class level, and to a lower taxonomic level (e.g. genus or species) when possible. Some unknown specimens were sent to specialists for identification.

Data were analysed using indices for diversity, richness and similarity as suggested by Chao \& Lee (1992), Lee \& Chao (1994) and Chao et al. (2005), using the SPADE software (Chao \& Shen 2005) and following recommendations from the software user guide for the choice of indices. These indices, most of which are non-parametric, are an extension of classical indices used in community ecology (Krebs 1989), taking into account 'unseen' species in estimates and using replicates to compute confidence intervals, allowing statistical comparisons. To obtain these indices for a given sampling station, we treated individual cidaroids as replicates for describing the 'cidaroid assemblages', as suggested by Shaw \& Dobson (1995) for host-parasite relationships, and single rocks as replicates for describing the 'rock assemblages'. The estimate of $S$, the species richness index of a given assemblage, was obtained using the abundance-based coverage estimator $\hat{S}_{A C E}$. The estimate of $H$, the species diversity index of a given assemblage, was obtained using the index $\hat{H}$ of Chao \& Shen (2003). Finally, the estimate of $J$, Jaccard's similarity index between assemblages, was computed from abundance-based data $\left(\hat{J}_{A}\right)$, according to the approach of Chao et al. (2005). 
The species abundance distributions (SADs) of sessile assemblages were also analysed according to methods reviewed by McGill et al. (2007). Such methods are independent of taxon identity and prevail for comparison of communities that do or do not share species. The rank abundance plot captures most of the information (McGill et al. 2007). Abundance data on a $\log _{10}$ scale were plotted against the rank of the species, from the most abundant (Rank 1) to the least abundant, and the distributions were inspected visually.

In order to find co-occurrence patterns of sessile organisms in the colonization of hard substrates (i.e. to determine whether the observed co-occurrence of epibionts departs from that expected by chance), we compared the observed species distribution with that generated by null models. Because the choice of a null model may influence the results (Gotelli 2000), the presence/absence matrices were analysed with 2 cooccurrence indices. Following Gotelli (2000) and Gotelli \& Rohde (2002), we chose $C$-score and $V$-ratio indices. Both are single-number measuring patterns for an entire presence/absence matrix. The $C$-score quantifies the degree of species co-occurrences; the larger the index, the less co-occurrence of species pairs. The $V$-ratio measures the community structure: this ratio is $>1$ for strong positive covariance between species pairs and $<1$ for strong negative covariance (see Gotelli 2000 for more details). The indices were calculated for each matrix (i.e. each sampling station) and compared with indices obtained for 5000 null communities randomly generated from the observed matrix. Again following Gotelli (2000), 2 null algorithms were chosen, mainly for their good statistical properties when used in association with the 2 indices (they are not prone to Type I and Type II errors). The first is the 'fixed-equiprobable' (f-e) algorithm: during the randomization process generating null matrices, the symbiont occurrences are fixed, but all sites have the same potential to be colonized. The second null algorithm is the 'fixed-fixed' (f-f) algorithm, where both symbiont occurrences and settlement sites are fixed. Here, the algorithm preserves differences among sites in the number of symbionts they contained. Therefore, in the $\mathrm{f}-\mathrm{f}$ model, the empty observed sites are not used to generate the null matrices, whereas, in the f-e model, all sites, including the empty ones, are considered suitable for colonization (Gotelli \& Rohde 2002). The difference between the 2 null models allowed us to test symbiont distributions considering either all sites or only the already colonized sites as available for attachment, a factor that was impossible to observe in situ due to the great depth of the sampling sites. Analyses and comparisons of observed versus simulated indices were conducted with the software EcoSim 7.0 (Gotelli \& Entsminger
2007) with a sequential swap algorithm creating the null matrices (Gotelli \& Rohde 2002). Finally, we applied another kind of null model, based on species density distributions (Janovy et al. 1995). For each sampling station, the observed sessile species density distribution (i.e. the observed number of hosts harbouring 0 to $n$ sessile taxa, $n$ being the maximum number of sessile taxa observed) was compared to the null model distribution (i.e. distribution independent of each colonizing event). This null model distribution was obtained using a multiple-kind lottery model (see Janovy et al. 1995 for details). This algorithm is a kind of $\mathrm{f}-\mathrm{e}$ model, as the observed frequencies of symbionts are used to generate the probabilities of colonization, but all fixation sites are equiprobably free for colonization. Comparisons of observed versus simulated distributions were made with a $\chi^{2}$ test (Janovy et al. 1995).

Comparisons of the sessile communities attached to rocks and on cidaroid spines were made at hierarchical spatial scales: inter-regions, intra-region but inter-stations, and intra-station. At the scale of the Weddell Sea (about $2000 \mathrm{~km}$ wide), we compared the 'rock assemblages' among 3 groups of stations: the eastern set $(E)$, the western subset of stations without cidaroids (W) and the western subset of stations with cidaroids $\left(\mathrm{W}^{*}\right)$ (Table 1). Within the western region, we compared assemblages at the scale of 100 s of kilometers by distinguishing the $\mathrm{W}$ and $\mathrm{W}^{*}$ stations, and, among the $\mathrm{W}^{*}$ subset, by distinguishing the rock assemblages $\left(\mathrm{W}^{*} \mathrm{r}\right)$ from the cidaroid assemblages $\left(\mathrm{W}^{*} \mathrm{C}\right)$. At this level of analysis, the sampling stations were individualized. The last order of comparisons concerned 'cidaroid assemblages' and 'rock assemblages' at the scale of 10 s of meters within the $2 \mathrm{~W}^{*}$ stations.

Statistical analyses were carried out using the software JMP v.6 (SAS Institute).

\section{RESULTS}

Rock size did not significantly differ between geographic groups of stations (E vs. $\mathrm{W}+\mathrm{W}^{*}$; ANOVA with 'group' as fixed factor and 'station' as random factor nested within 'group': $F_{9,128}=1.51, \mathrm{p}=0.15$ for diameter and $F_{9,128}=1.23, \mathrm{p}=0.28$ for height), allowing comparison of their colonization. Cidaroids, with their spines, were not significantly different in height from rocks at each station where they were found in common ( $\mathrm{W}^{*}$ stations) (Table $1 ; t=-1.11, \mathrm{p}=0.30$ at Stn 142; $t=0.86, \mathrm{p}=0.39$ at $\operatorname{Stn} 151$ ).

Within the $2 \mathrm{~W}^{*}$ sites (Stn 142 harboured only Aporocidaris milleri, while Stn 151 harboured only Ctenocidaris speciosa), cidaroids were less numerous than rocks, but the number of sessile animals they carried was higher than that of rocks (Table 1; Fisher 
exact test, 2-tailed $p<0.005$ in all cases). The proportion on colonized rocks was also variable between stations (Table 1; Pearson $\chi^{2}=60.80, \mathrm{p}<0.0001$ ). Across stations, there was no correlation between average rock size and the rate of colonization (Spear$\operatorname{man} \rho=0.19, p=0.59$ ). The distributions of sessile taxa colonizing each station are given in detail in Appendix 1, Table S1 available in MEPS Supplementary Material at www.int-res.com/articles/suppl/m364 p067_app.pdf).

Global analysis of the rock assemblages at a large spatial scale revealed that SADs were comparable on both sides of the Weddell Sea. In addition, in the western samples, the presence or absence of cidaroids did not substantially modify the SAD of rock assemblages (Fig. 2A). The general pattern of these SADs is a lack of dominant species (none was found with a total exceeding 100 individuals) and a slight excess of rare species. Diversity (Fig. 2B) and richness (Fig. 2C) did not significantly differ between the different groups of stations. In addition, rocks from $\mathrm{E}$ and $\mathrm{W}$ stations harboured very similar sessile faunas, sharing about $75 \%$ of taxa (Fig. 2D). However, in the western region, only $30 \%$ of the taxa were shared between rocks from stations with and without cidaroids (Fig. 2D). Generally, while diversity and distribution of organisms attached to rocks are relatively homogenous across the Weddell Sea, their species composition seems to be affected by the local presence of cidaroids. Therefore, 'rock assemblages' might be echinoid-sensitive. Indeed, the SADs for the $\mathrm{W}^{*}$ stations, when including the cidaroids, departed strongly from those for rocks only (Fig. 2A).

Comparison of stations within the western Weddell Sea confirmed the general pattern. Stations without cidaroids (W) exhibited rock assemblages with a comparable magnitude of species richness (Fig. 3A), the only significant difference being between Stns 152 and 121. Total species richness of $\mathrm{W}^{*}$ stations (with cidaroids) was significantly higher than that of $\mathrm{W}$ stations (Fig. 3A), with the exception of comparisons involving Stn 152, for which the confidence interval was very large. The high species richness in $\mathrm{W}^{*}$ stations was not due to a higher species richness on cidaroids, but rather due to the combination of the 2 sub-faunas (rock fauna plus cidaroid fauna, right part of Fig. 3A). Species diversity was not found to be altered or enhanced by the presence of cidaroids, the values of $\hat{H}$ for total fauna (rocks plus cidaroids) falling within the same range in $\mathrm{W}$ or $\mathrm{W}^{*}$ stations (Fig. 3B). Moreover, at Stn 142, species diversity of the cidaroid sub-faunas was lower than that found on rocks (Fig. 3B), probably because of the presence of numerically predominant taxa (see Fig. 4A). Among the $\mathrm{W}$ and $\mathrm{W}^{*}$ stations, the similarities of rock assem-
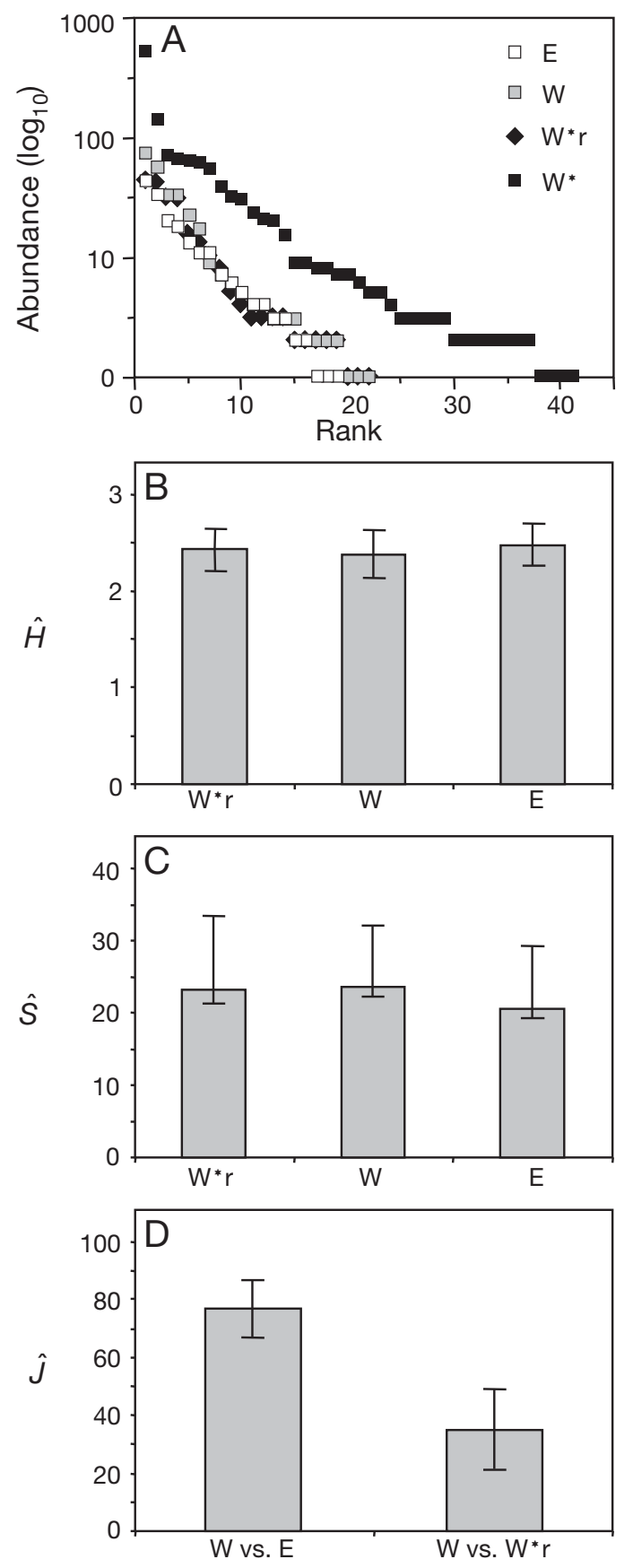

Fig. 2. Large-scale comparison of rock sessile fauna, denoted by an $r$, between groups of stations (E: stations in the eastern part of the Weddell Sea without cidaroids; W: stations in the western part of the Weddell Sea without cidaroids; $\mathrm{W}^{*} \mathrm{r}$ : stations in the western part of the Weddell Sea with cidaroids). (A) Species abundance distribution (rank-abundance plot) of rock sessile fauna for the 3 groups of stations, compared with the total fauna found in $\mathrm{W}^{*}$ stations (fauna on both rocks and cidaroids). (B) Specific diversity, estimated using the index by Chao \& Shen (2003). (C) Specific richness, estimated using the abundance-based coverage estimator. (D) Similarity between groups of stations evaluated by Jaccard's index estimator, based on abundance as proposed by Chao et al. (2005). Error bars are $95 \%$ confidence intervals 

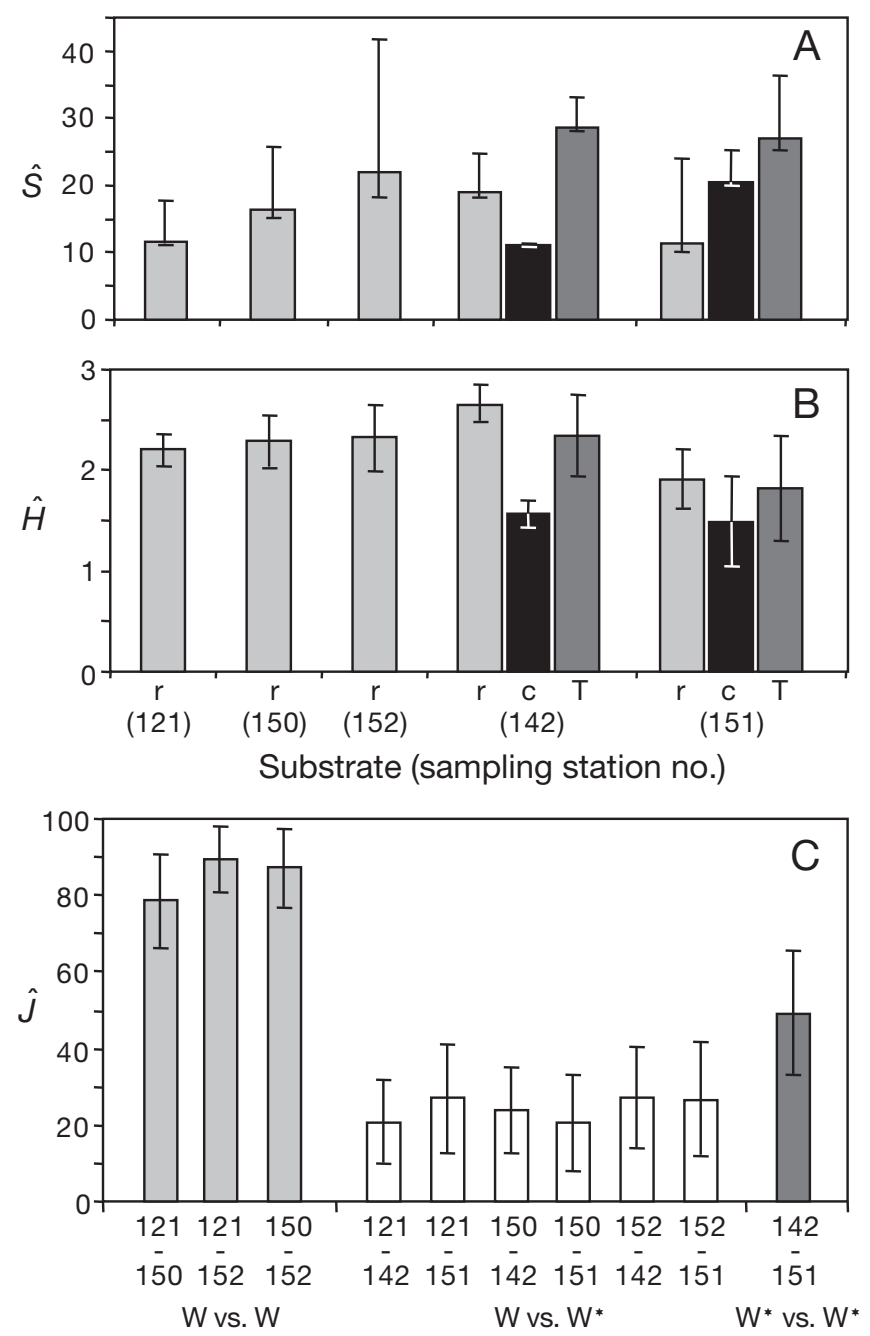

Fig. 3. Characteristics of sessile fauna within and between stations in the western Weddell Sea. (A) Species richness within stations according to substrate type (r: rocks; c: cidaroids; T: total [rocks + cidaroids]). (B) Specific diversity within stations, according to the substrate type (r: rocks; $\mathrm{C}$ : cidaroids; $\mathrm{T}$ : total [rocks + cidaroids]). (C) Between-station similarities of rock sessile faunas. Comparisons were made either between W stations (stations without cidaroids), between $\mathrm{W}$ and $\mathrm{W}^{*}$ stations (stations with cidaroids), or between the $2 \mathrm{~W}^{*}$ stations. Error bars are $95 \%$ confidence intervals

blages were very variable (Fig. 3C). The rocks of the 3 W stations shared most of their sessile fauna (>80\% taxa in common). However, rocks from $\mathrm{W}$ and $\mathrm{W}^{*}$ shared a significantly lower proportion of their sessile fauna (20 to $30 \%$ ) (Fig. 3C). Rocks from the $2 \mathrm{~W}^{*}$ stations showed an intermediate pattern and shared about half of the taxa.

At a local scale, the SADs of sessile fauna at $\mathrm{W}^{*}$ stations were split into 2 sub-samples: the fauna found on rocks and the fauna found on cidaroids. The 2 SADs obtained were different, as abundant and medium-
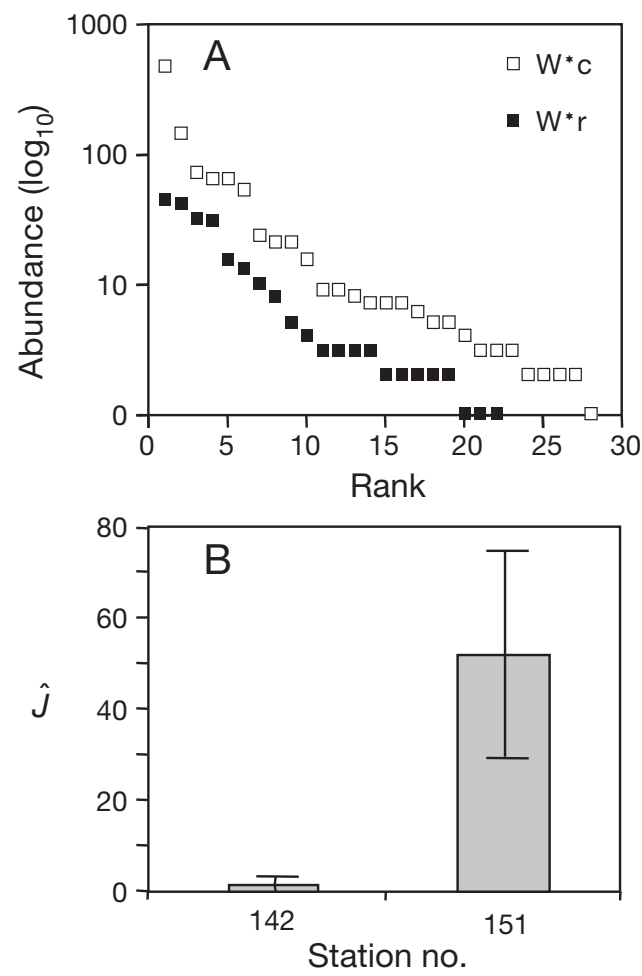

Fig. 4. Characteristics of the sessile fauna within the stations in the western part of the Weddell Sea including cidaroids $\left(\mathrm{W}^{*}\right.$ stations). (A) Species abundance distributions (rank-abundance plot) of fauna on cidaroids $\left(\mathrm{W}^{*} \mathrm{c}\right)$ and rocks $\left(\mathrm{W}^{*} \mathrm{r}\right)$. Log abundance is plotted against the rank of the species. (B) Similarities between rock and cidaroid assemblages, within the $2 \mathrm{~W}^{*}$ stations. Error bars are $95 \%$ confidence intervals

abundant taxa were, relatively, most frequent on cidaroids but not on rocks (Fig. 4A). Within each $\mathrm{W}^{*}$ station, the average similarity between cidaroid and rock assemblages was low. This was especially true at Stn 142 , with $<5 \%$ of species shared by the 2 types of substrates (Fig. 4B). Similarity was significantly different and higher at Stn 151, where about $50 \%$ of species were shared between substrates, with large variation around this estimate (Fig. 4B). However, we can hardly assume that sessile assemblages living on cidaroids are similar to those living on rocks. In addition, the species shared by cidaroids and rocks were not the more common species found at both $\mathrm{W}^{*}$ stations (Appendix 1, Table S1): the prevalence distributions of shared versus unshared species were not significantly different on rocks (Wilcoxon non-parametric test: $Z=$ $0.47, \mathrm{p}=0.65)$ or on cidaroids $(Z=0.13, \mathrm{p}=0.89)$. The 2 stations were pooled for this analysis, because there was no difference between stations in the prevalence of sessile organisms on rocks $(Z=-0.71, \mathrm{p}=0.47)$ or on cidaroids $(Z=-0.77, \mathrm{p}=0.44)$. For example, at Stn 151, the shared 'Foraminifera A' was one of the most prevalent and abundant taxa on both the cidaroid Ctenoci- 
daris speciosa and rocks, while the shared 'Porifera B' was among the rarest.

Co-occurrence patterns in colonization were investigated within each station. With very few exceptions, the null algorithms with equiprobable colonizing sites (f-e models) led to the same result. At stations without cidaroids, communities of sessile organisms were highly structured, showing a pattern of aggregation and more co-occurrence than to be expected by chance (Table 2). At stations where cidaroids were present, the overall species distribution (i.e. taxa found either on rocks or on cidaroids, or both) also departed significantly from the null models. This was also observed for the rock assemblages alone at these stations (Table 2). However, the cidaroid assemblages never significantly differed from null model distributions, whatever the algorithm used. The $\mathrm{f}-\mathrm{f}$ model provided very different results, and no clear pattern emerged when analysing sessile communities attached to rocks. This means that, if we consider

Table 2. Comparison of observed versus simulated number of different ectosymbiont taxa per attachment site (i.e. rock or cidaroid), by sampling station. The 4 right-hand columns give significance of deviations from the null hypotheses (i.e. random distribution of symbionts). Density distribution: null model for species density distribution; $C$-score f-e: $C$-score index tested with the fixed-equiprobable null model; $V$-ratio f-e: $V$-ratio index tested with the fixed-equiprobable null model $; C$-score $\mathrm{f}-\mathrm{f}$ : $C$-score index tested with the fixed-fixed null model; $\mathrm{T}$ : total available substrates (cidaroids + rocks); c: cidaroids; r: rocks; A: a deviation in the direction of aggregation (more species cooccurrence than expected by chance); S: a deviation in the direction of segregation (less species co-occurrence than expected by chance); n.s. not significant; $\mathrm{p}>0.05 ;{ }^{*} \mathrm{p}<0.05 ;{ }^{* *} \mathrm{p}<$ $0.01 ;{ }^{* * * *} p<0.0001$. For density distribution, tests are 2 -tailed, and the direction of deviation was estimated after examination of distributions (see Appendix 1, Table S2 available in MEPS Supplementary Material at www.int-res.com/articles/suppl/ m364p067_app.pdf); for other null models and indices, tests are 1-tailed

\begin{tabular}{|c|c|c|c|c|}
\hline $\begin{array}{l}\text { Sampling } \\
\text { station }\end{array}$ & $\begin{array}{c}\text { Density } \\
\text { distribution }\end{array}$ & $\begin{array}{c}C \text {-score } \\
\text { f-e }\end{array}$ & $\begin{array}{c}V \text {-ratio } \\
\mathrm{f}-\mathrm{e}\end{array}$ & $\begin{array}{c}C \text {-score } \\
\mathrm{f}-\mathrm{f}\end{array}$ \\
\hline $57 \mathrm{r}$ & $A^{*}$ & $\mathrm{~A}^{* *}$ & $\mathrm{~A}^{* *}$ & n.s. \\
\hline $59 \mathrm{r}$ & $\mathrm{A}^{* * * * *}$ & $\mathrm{~A}^{* * * * *}$ & $\mathrm{~A}^{* * * *}$ & n.s. \\
\hline $78 \mathrm{r}$ & $\mathrm{A}^{* * * *}$ & $\mathrm{~A}^{* * * * *}$ & $\mathrm{~A}^{* * * *}$ & $\mathrm{~A}^{* *}$ \\
\hline 80r & $\mathrm{A}^{* * * *}$ & $\mathrm{~A}^{* * * *}$ & $\mathrm{~A}^{* * * *}$ & n.s. \\
\hline $94 \mathrm{r}$ & $\mathrm{A}^{* * * *}$ & $\mathrm{~A}^{* * * *}$ & $\mathrm{~A}^{* * * *}$ & n.s. \\
\hline $121 \mathrm{r}$ & n.s. & $\mathrm{A}^{* *}$ & $\mathrm{~A}^{* *}$ & n.s. \\
\hline $150 \mathrm{r}$ & $\mathrm{A}^{* * * *}$ & $\mathrm{~A}^{* * * *}$ & $\mathrm{~A}^{* * * *}$ & n.s. \\
\hline $152 \mathrm{r}$ & $\mathrm{A}^{* * * *}$ & $\mathrm{~A}^{* * * *}$ & $\mathrm{~A}^{* * * * *}$ & n.s. \\
\hline $142 \mathrm{~T}$ & $\mathrm{~A}^{* * * *}$ & $\mathrm{~A}^{* * * *}$ & $\mathrm{~A}^{* * * *}$ & $\mathrm{~S}^{* * * *}$ \\
\hline $142 \mathrm{r}$ & $\mathrm{A}^{* * * *}$ & $\mathrm{~A}^{* * * * *}$ & $\mathrm{~A}^{* * * *}$ & n.s. \\
\hline $142 \mathrm{C}$ & n.s. & n.s. & n.s. & n.s. \\
\hline $151 \mathrm{~T}$ & $\mathrm{~A}^{* * * * *}$ & $\mathrm{~A}^{* * * * *}$ & $\mathrm{~A}^{* * * *}$ & $\mathrm{~S}^{* * * *}$ \\
\hline $151 \mathrm{r}$ & $\mathrm{A}^{* * * *}$ & $\mathrm{~A}^{* * * *}$ & $\mathrm{~A}^{* * * * *}$ & n.s. \\
\hline $151 \mathrm{C}$ & n.s. & n.s. & n.s. & n.s. \\
\hline
\end{tabular}

uncolonized rocks as unavailable (the algorithm is actually doing that), the sessile communities did not show any aggregative pattern. On the other hand, the analysis of the total sessile communities at stations harbouring both rocks and cidaroids showed highly significant segregation between sessile species (Table 2). Since the unoccupied rocks were not considered in this analysis, and since the same analysis performed on rocks and cidaroids separately provided non-significant results (Table 2), this indicates a strong segregation between the sessile fauna fixed on rocks and that attached to cidaroids.

\section{DISCUSSION}

Our results suggest that the presence of cidaroid echinoids modifies the local diversity of the deep-sea sessile benthos in the Weddell Sea. It is worth noting that the assemblages of sessile faunas were quite similar on rocks across the Weddell Sea (Fig. 2), but very different between cidaroids and rocks within the same local sampling stations (Fig. 4). The observed pattern is that the presence of cidaroids generally promoted a higher total species richness (i.e. species fixed on both rocks and cidaroids), and allowed some species already present to become dominant (e.g. Foraminifera A), but also allowed the, sometimes abundant, settlement of additional species (e.g. Hydrozoa A). In addition, while different species were attached to rocks and cidaroids, respectively, the overall species diversity remained approximately the same.

The cidaroid ectosymbiotic fauna can be richer or poorer than that on rocks, but it seems generally less diverse, with more very abundant species. Our results suggest that sessile communities in the Weddell Sea are not composed of generalist species able to settle on all available substrates. Such a situation is reminiscent of the fauna attached to hermit crab shells in the Mediterranean Sea (Bick 2006), where some specificity was observed. We propose that the presence of cidaroids provides specific ecological niches for sessile organisms, thereby strongly influencing local biodiversity at this level. This confirms observations by Gutt \& Schickan (1998), but at a local scale and relying on consistent comparisons within the same sampling sites (the same micro-habitats).

Differences in sessile assemblages were found between the 2 stations with cidaroids. This suggests that cidaroid-specific characteristics are likely to also influence ectosymbiont diversity and distribution. Clearly, more studies are needed to investigate what these characteristics could be (morphological, chemical, or otherwise). For instance, cidaroid spine shape and roughness not only vary between species, but also 
along the shaft within a given species (Hétérier et al. 2004, David et al. 2005a,b). Spine morphologies could thus have a discriminative effect on the settlement and development of associated species and could explain some differences in the distribution of ectosymbionts, a hypothesis amenable to manipulative experiments. Behavioural differences between hosts could also explain such differences, as observed between encrusting communities on gastropods shells and shells used by hermit crabs (Bell 2005).

At stations where both cidaroids and rocks were present, comparison of their respective sessile fauna indicates that the abundance of species on echinoids is generally higher than the abundance of species on rocks. In addition, the SAD of taxa on cidaroids showed no excess of rare species, while the distribution is leftskewed on rocks (they host more rare species). Recently, several community subdivisions (also called deconstructions), either temporal (Magurran \& Henderson 2003, Ulrich \& Ollik 2004) or spatial (Ulrich \& Zalewski 2006), into 'core' species versus transient or satellite species have shown that left-skewed SADs can often be attributed to the fact that species that are non-permanently present in the community occur only occasionally, thus generating an overall disproportionate number of rare species. The pattern recorded for the deep Weddell Sea is similar, but, following the abovementioned interpretation, one would consider that core sessile species in the Weddell Sea are the cidaroid ectosymbionts, while the satellite fauna would be the one colonizing rocks. Such a situation is unexpected, since rocks as settlement sites are much more available and predictable than cidaroids. Therefore, the observed distribution pattern remains to be fully understood, but a tentative explanation can be proposed. Most of the epibionts found on rocks and cidaroids were filter-feeding organisms that need to be in the water flow to optimize their food uptake (Gutt \& Schickan 1998). Although they can sometimes be as high as cidaroids, rocks can sink into and become covered with mud, while cidaroid spines offer sessile organisms a higher position in the water column. Rocks can be seen as a less favourable habitat for sessile fauna than cidaroids. Prevention from burial has been shown to be one of the benefits gained by symbionts of hermit crabs (Williams \& McDermott 2004). Gutt \& Schickan (1998) proposed that sessile species would opportunistically colonize living substrates, rather than rocks. Nevertheless, our results do not support an opportunistic colonization of cidaroids, since their ectosymbiotic fauna differs from epibionts of rocks. However, because cidaroids are much rarer than rocks, colonization of the favourable micro-sites (spines) could be achieved by some specialists reaching high abundance, leaving the unfavourable rocks sites to generalists unable to reach high abundances. In the Antarctic, the rock-cidaroid differences in sessile fauna composition and abundance could therefore be due to differences in colonizing dynamics of specialist versus generalist species.

Comparison of co-occurrence patterns of sessile organisms between rocks and cidaroids tend to support this point of view. Settlement on rocks deviated from the null models at all stations when algorithms considered all sites equiprobably available for fixation. The observed excess of co-occurrence on rocks confirms that the majority is not suitable for sessile organisms. This could be due to the fact that some of these rocks were partially buried in the mud and therefore not fully accessible to colonization. However, if the non-colonized rocks were not considered in the analysis (f-f model), no aggregative pattern was found. This means that settlement on available rocks by a given species was hardly influenced by other species. Contrasting with the pattern recorded on rocks, species distribution on cidaroids always agreed with the null model distribution, suggesting that there is no species interaction for cidaroid colonization. This could indicate favourable attachment sites, where the occurrence of a given sessile organism is independent of the presence of other species. Finally, the strong segregation pattern observed, using the $\mathrm{f}-\mathrm{f}$ null model, between rock and cidaroid assemblages at the same sampling stations strengthens the hypothesis of cidaroid colonization by specialist organisms.

To conclude, our study suggests that the presence of cidaroids may modulate benthic biodiversity in the Antarctic by providing attachment sites for ectosymbionts on their naked spines. Although more studies, investigating more cidaroid species and more biotopes, particularly in shallower water, are needed to confirm this assumption, the present study contributes to the understanding of the effects of species interactions on biodiversity (see also Clay 2001). It generates hypotheses that can be tested with other organisms in the Antarctic (see Gutt \& Schickan 1998 for other organisms acting as substratum for sessile forms). Finally, it supports the hypothesis that cidaroids might be key species of the benthic Antarctic deep-sea ecosystem, facilitating the settlement of many others.

Acknowledgements. This work is part of the BIANZO I (EV/11/24C) and II (SD/BA/02A) projects supported by the Belgian Science Policy (PADDII projects). V.H. was supported by a $\mathrm{PhD}$ grant from the Belgian Science Policy. This is a contribution of the teams 'Ecologie Evolutive' and 'Forme, Evolution, Diversité' of the CNRS laboratory Biogéosciences and of the CIBIM (Centre inter-universitaire de Biologie Marine). We thank all participants of the ANDEEP III expedition of the RV 'Polarstern' (ANT XXII/3). We are also extremely grateful to D. Pawson and R. Poulin for their productive comments on the manuscript. 


\section{LITERATURE CITED}

Allcock AL, Piatowski U, Rodhouse PGK, Thorpe JP (2001) A study on octopodids from the eastern Weddell Sea, Antarctica. Polar Biol 24:832-838

Andrews JT, Smith LM, Preston R, Cooper T, Jennings AE (1997) Spatial and temporal patterns of iceberg rafting (IRD) along the east Greenland margin, ca. 68 degrees N, over the last $14 \mathrm{cal}$ ka. J Quaternary Sci 12:1-13

Arntz WE, Brey T, Gallardo VA (1994) Antarctic zoobenthos. Oceanogr Mar Biol 32:251-303

Barnes DKA, Clarke A (1995) Epibiotic communities on sublittoral macroinvertebrates at Signy Island, Antarctica. J Mar Biol Assoc UK 75:689-703

Battaglia B, Valencia J, Walton D (1997) Antarctic communities: species, structure and survival. Cambridge University Press, Cambridge

Begon MB, Harper JL, Townsend CR (1996) Ecology: individuals, populations and communities, 3rd edn. Blackwell Science, Oxford

Bell JJ (2005) Influence of occupant microhabitat on the composition of encrusting communities on gastropod shells. Mar Biol 147:653-661

Bick A (2006) Polychaete communities associated with gastropod shells inhabited by the hermit crabs Clibanarius erythropus and Calcinus tubularis from Ibiza, Mediterranean Sea. J Mar Biol Assoc UK 86:83-92

Brandt A, Gooday AJ, Brandao SN, Brix S and others (2007) First insights into the biodiversity and biogeography of the Southern Ocean deep sea. Nature 447:307-311

Brey T, Starmans A, Magiera U, Hain S (1993) Lissarca notorcadensis (Bivalvia: Philobryidae) living on Notocidaris sp. (Echinoidea: Cidaridae): population dynamics in limited space. Polar Biol 13:89-95

Brey T, Klages M, Dahm C, Gorny M and others (1994) Antarctic benthic diversity. Nature 368:297

> Chao A, Lee SM (1992) Estimating the numbers of classes via sample coverage. J Am Stat Assoc 87:210-217

> Chao A, Shen TJ (2003) Nonparametric estimation of Shannon's index of diversity when there are unseen species in samples. Environ Ecol Stat 10:429-443

Chao A, Shen TJ (2005) Program SPADE (species prediction and diversity estimation). Available at: http://chao.stat. nthu.edu.tw

> Chao A, Chazdon RL, Colwell RK, Shen TJ (2005) A new statistical approach for assessing similarity of species composition with incidence and abundance data. Ecol Lett 8: 148-159

Clarke A, Jonhson NM (2003) Antarctic marine benthic diversity. Oceanogr Mar Biol 41:47-114

Clarke A, Griffiths HJ, Linse K, Barnes DKA, Crame JA (2007) How well do we know the Antarctic marine fauna? A preliminary study of macroecological and biogeographical patterns in Southern Ocean gastropod and bivalve molluscs. Diversity Distrib 13:620-632

Clay K (2001) Symbiosis and the regulation of communities. Am Zool 41:810-824

Clay K, Holah J (1999) Fungal endophyte symbiosis and plant diversity in sucessional fields. Science 285:1742-1744

David B, Choné T, Mooi R, De Ridder C (2005a) Antarctic Echinoidea. Synopses of the Antarctic benthos, 10. Koeltz Scientific Books, Königstein

David B, Choné T, Festeau A, Mooi R, De Ridder C (2005b) Biodiversity of Antarctic echinoids: a comprehensive and interactive database. Sci Mar 69(Suppl. 2):201-203

Gotelli NJ (2000) Null model analysis of species co-occurrence patterns. Ecology 81:2606-2621
Gotelli NJ, Entsminger GL (2007). EcoSim: null models software for ecology, Version 7. Acquired Intelligence \& Kesey-Bear, Jericho, Vermont. http://garyentsminger. com/ecosim.htm

Gotelli NJ, Rohde K (2002) Co-occurrence of ectoparasites of marine fishes: a null model analysis. Ecol Lett 5:86-94

Gutt J (2000) Some 'driving forces' structuring communities of the sublittoral Antarctic macrobenthos. Antarct Sci 12: 297-313

Gutt J, Schickan T (1998) Epibiotic relationships in the Antarctic benthos. Antarct Sci 10:398-405

Gutt J, Starmans A (1998) Structure and biodiversity of megabenthos in the Weddell and Lazarev Seas (Antarctica): ecological role of physical parameters and biological interactions. Polar Biol 20:229-247

> Hatcher MJ, Dick JTA, Dunn AM (2006) How parasites affect interactions between competitors and predators. Ecol Lett 9:1253-1271

Hétérier V, De Ridder C, David B, Rigaud T (2004) Comparative biodiversity of ectosymbionts in two Antarctic cidarid echinoids, Ctenocidaris spinosa and Rhynchocidaris triplopora. In: Heinzeller T, Nebelsick JH (eds) Echinoderms München. Taylor \& Francis, London, p 201-205

Hilbig B (2001) Deep-sea polychaetes in the Weddell Sea and Drake Passage: first quantitative results. Polar Biol 24: 538-544

Hopkins TS, Thompson LE, Walker JM, Davis M (2004) A study of epibiont distribution on the spines of the cidaroid sea urchin, Eucidaris tribuloides (Lamarck, 1816) from the shallow shelf of the eastern Gulf of Mexico. In: Heinzeller T, Nebelsick JH (eds) Echinoderms München. Taylor \& Francis, London, p 207-211

Jacob U, Terpstra S, Brey T (2003) High-Antarctic regular sea urchins - the role of depth and feeding in niche separation. Polar Biol 26:99-104

> Janovy J, Clopton RE, Clopton DA, Snyder SD, Efting A, Krebs L (1995) Species density distributions as null models for ecologically significant interactions of parasite species in an assemblage. Ecol Modell 77:189-196

Jones CG, Lawton JH, Shachak M (1994) Organisms as ecosystem engineers. Oikos 69:373-386

Key MM, Jeffries WB, Voris HK (1996) Epizoic bryozoans, horseshoe crabs, and other mobile benthic substrates. Bull Mar Sci 58:368-384

Knox GA (1994) The biology of the Southern Ocean. Studies in polar research. Cambridge University Press, Cambridge

Krebs CJ (1989) Ecological methodology. Harper \& Row, New York

Lee SM, Chao A (1994) Estimating population size via sample coverage for closed capture-recapture models. Biometrics 50:88-97

Linse K, Griffiths HJ, Barnes DKA, Clarke A (2006) Biodiversity and biogeography of Antarctic and sub-Antarctic mollusca. Deep-Sea Res II 53:985-1008

Linse K, Brandt A, Bohn JM, Danis B and others (2007) Macro- and megabenthic assemblages in the bathyal and abyssal Weddell Sea (Southern Ocean). Deep-Sea Res II 54:1848-1863

> Magurran AE, Henderson P (2003) Explaining the excess of rare species in natural species abundance distributions. Nature 422:714-716

- Märkel K, Röser U (1983) Calcite resorption in the spine of the echinoid Eucidaris tribuloïdes. Zoomorphology 103:43-58

> Massin C, Hétérier V (2004) On a new species of apodid, Taeniogyrus magnibaculus n. sp. (Echinodermata, Holothuroidea), from Antarctica, living on the spines of cidaroid echinoids. Polar Biol 27:441-444 
McGill BJ, Etienne RS, Gray JS, Alonso D and others (2007) Species abundance distributions: moving beyond single prediction theories to integration within an ecological framework. Ecol Lett 10:995-1015

Ragua-Gil JM, Gutt J, Clarke A, Arntz WE (2004) Antarctic shallow-water mega-epibenthos: shaped by circumpolar dispersion or local conditions. Mar Biol 144:829-839

Schneider CL (2003) Hitchhiking on Pennsylvanian echinoids: epibionts on archeocidaris. Palaios 18:435-444

Shaw DJ, Dobson AP (1995) Patterns of macroparasite abundance and aggregation in wildlife populations: a quantitative review. Parasitology 111:S111-S133

Starmans A, Gutt J, Arntz WE (1999) Mega-epibenthic com-

Editorial responsibility: John Lawrence,

Tampa, Florida, USA munities in Arctic and Antarctic shelf areas. Mar Biol 135: 269-280

Tyler PA (1995) Conditions for the existence of life at the deep-sea floor: an update. Oceanogr Mar Biol 33:221-244

Ulrich W, Ollik M (2004) Frequent and occasional species and the shape of relative-abundance distributions. Divers Distrib 10:263-269

Ulrich W, Zalewski M (2006) Abundance and co-occurrence patterns of core and satellite species of ground beetles on small lake islands. Oikos 114:338-348

Williams JD, McDermott JJ (2004) Hermit crab biocoenoses: a worldwide review of the diversity and natural history of hermit crab associates. J Exp Mar Biol Ecol 305:1-128

Submitted: December 20, 2007; Accepted: March, 2008 Proofs received from author(s): July 3, 2008 